\title{
CATATAN BARU GYMNOPETALUM SCABRUM (LOUR.) W.J.DE WILDE \& DUYFJES UNTUK BORNEO
}

\author{
Mentari Putri Pratami ${ }^{1}$, Tatik Chikmawati ${ }^{2}$ \& Rugayah $^{3}$ \\ ${ }^{1}$ Program Studi Biologi Tumbuhan, Sekolah Pascasarjana Institut Pertanian Bogor. Kampus Dramaga, Bogor \\ 16680. \\ ${ }^{2}$ Departemen Biologi, Fakultas Matematika dan Ilmu Pengetahuan Alam, Institut Pertanian Bogor. Kampus \\ Dramaga, Bogor 16680. \\ ${ }^{3}$ Bidang Botani, Pusat Penelitian Biologi, Lembaga Ilmu Pengetahuan Indonesia, Cibinong 16911. \\ Korespondensi: tchikmawati@yahoo.com
}

Mentari Putri Pratami, Tatik Chikmawati \& Rugayah. 2019. A New Record of Gymnopetalum scabrum (Lour.) W.J.De Wilde \& Duyfjes for Borneo. Floribunda 6(3): 93-97. - Gymnopetalum scabrum is spread in the Malesia region, but has not been reported in Borneo. This species was found on the road sides and near the river, Samboja, East Kalimantan. Its description and distribution is presented in this paper.

Keywords: Cucurbitaceae, distribution, Gymnopetalum, Borneo, new record.

Mentari Putri Pratami, Tatik Chikmawati \& Rugayah. 2019. Catatan Baru Gymnopetalum scabrum (Lour.) W.J.De Wilde \& Duyfjes untuk Borneo. Floribunda 6(3): 93-97. - Jenis Gymnopetalum scabrum tersebar di Kawasan Malesia, namun di wilayah Borneo sebelumnya belum pernah dilaporkan. Jenis tersebut ditemukan di tepi jalan raya dan dekat sungai, Samboja, Kalimantan Timur. Deskripsi dan persebaran jenisnya disajikan dalam tulisan ini.

Kata kunci: Cucurbitaceae, Gymnopetalum, Borneo, persebaran, rekaman baru.

Marga Gymnopetalum secara taksonomi merupakan kerabat dekat Trichosanthes yang terdiri atas 4 jenis yaitu $G$. tubiflorum, G. integrifolium, $G$. chinense, dan G. orientale. G. integrifolium tersebar luas dan dua koleksi BO dari jenis ini yang berasal dari Jawa Timur ditetapkan sebagai var. pectinatum. Selain itu, spesimen dari China (Hainan) jenis ini dengan tepi daun bergigi diajukan sebagai var. penicaudii (de Wilde et al. 2015). Adapun $G$. orientale memiliki ciri yang mirip dengan anggota Trichosanthes berdasarkan kehadiran probract yang mencolok pada nodus, yang dianggap sebagai ciri perantara antara dua marga. Perbedaan antara kedua marga terletak pada ciri bunga, selain ada atau tidaknya benang pada pinggiran kelopak (ciri khas Trichosanthes), adalah bentuk keseluruhan kelopak yang terlipat pada tunas dewasa yaitu pendek dan bulat pada Trichosanthes dan memanjang, lebih panjang dan luas pada Gymnopetalum. Tiga marga lain dari India utara menyerupai Gymnopetalum yaitu Edgaria C.B. Clarke (ciri biji berbeda), Biswarea Cogn. dan Herpetospermum Wall. (dua yang terakhir berbeda pada kelopak bunga yang menyatu pada pangkalnya dan \pm 3 buah mengatup) (de Wilde \& Duyfjes 2006).

Secara filogeni berdasarkan penanda molekuler, Trichosanthes dan Gymnopetalum oleh de
Boer \& Thulin (2012) memiliki implikasi nomenklatur untuk jenis Gymnopetalum dan klasifikasi infragenerik Trichosanthes. Jenis Gymnopetalum ditempatkan di berbagai klada dalam Trichosanthes. Menurut Boer et al. (2012), bukti molekuler menujukkan bahwa Gymnopetalum monofiletik dengan Trichosanthes, selain itu berdasarkan data filogeni molekuler mengungkap bahwa kelopak berumbai panjang berevolusi secara independen pada marga Hodgsonia dan Trichosanthes/Gymnopetalum.

Gymnopetalum Arn. di kawasan Malesia dilaporkan ada 3 jenis yaitu $G$. chinense (Lour.) Merr., G. orientale W.J.de Wilde \& Duyfjes dan G. scabrum (Lour.) W.J.de Wilde \& Duyfjes dengan 2 varietas ( $G$. scabrum var. scabrum dan $G$. scabrum var. pectinatum). Jenis $G$. chinense (Lour.) Merr. tersebar luas, jenis $G$. orientale W.J.de Wilde \& Duyfjes hanya dijumpai di P. Sulawesi, Kep. Sunda Kecil dan Maluku, sedangkan G. scabrum (Lour.) W.J.de Wilde \& Duyfjes terdapat di seluruh kawasan Malesia kecuali Sumatera dan Borneo (de Wilde \& Duyfjes 2010). Pada tahun 2015, de Wilde et al. mengubah status salah satu varietas yaitu G. scabrum var. pectinatum menjadi jenis yang berbeda sehingga di kawasan Malesia marga ini bertambah menjadi empat jenis yaitu $G$. chinense, G. oriantale, $G$. 
scabrum, dan G. pectinatum.

Spesimen herbarium Gymnopetalum scabrum di Herbarium Bogoriense (BO) telah diamati sebanyak 15 lembar dan hanya tersimpan spesimen yang berasal dari P. Jawa. Penambahan koleksi baru tersebut mengubah status persebarannya dan sebanyak satu koleksi dicatat sebagai rekaman baru untuk Borneo dikarenakan di buku Flora Malesiana tercatat bahwa spesimen G. scabrum tidak diketahui keberadaannya di Borneo dan Sumatera. Dengan laporan ini, jumlah jenis Gymnopetalum yang tumbuh di Borneo menjadi 2 jenis yaitu $G$. chinense dan G. scabrum.

\section{BAHAN DAN METODE}

\section{Bahan}

Bahan yang digunakan adalah spesimen $G$. scabrum yang telah dikoleksi oleh MHF (Miftahul Huda Fendiyanto)01 dan spesimen herbarium yang tersimpan di Herbarium Bogoriense (BO) sebanyak 15 lembar. Spesimen yang telah dikoleksi kemudian diidentifikasi di Laboratorium Ekologi dan Sumberdaya Tumbuhan, Departemen Biologi, FMIPA IPB.

\section{Pengambilan Sampel}

Kegiatan eksplorasi yang dilakukan pada tanggal 24 Februari 2017 di daerah Samboja, Kalimantan Timur, menemukan material dengan nomor koleksi MHF01, tumbuh di tepi jalan raya dekat sungai yang diidentifikasi sebagai jenis G. scabrum. Berdasarkan pemeriksaan herbarium jenis G. scabrum di Herbarium Bogoriense hanya terdapat spesimen yang berasal dari Jawa dan tidak ditemukan spesimen yang berasal dari Borneo.

Eksplorasi dilakukan dengan metode jelajah yaitu dengan menjelajahi kebun dan mengoleksi sampel yang ada di sekitar hutan atau kebun tersebut (Rugayah dkk. 2004). Hasil eksplorasi dikoleksi dan dibuat herbarium dengan memberikan catatan mengenai informasi nama jenis, lokasi ditemukan, tanggal koleksi, kolektor, suhu, dan ketinggian.

\section{Pengamatan}

Ciri yang diamati meliputi morfologi batang, daun, bunga, buah, dan biji. Istilah botani yang digunakan mengikuti Radford (1986), Glosarium Biologi oleh Rifai \& Puryadi (2008), dan Harris \& Harris (2006).

\section{HASIL DAN PEMBAHASAN}

Gymnopetalum tercatat ada 2 jenis yang tersebar di Borneo. Kedua jenis tersebut dapat di identifikasi dengan menggunakan kunci determinasi sebagai berikut:

\section{Kunci identifikasi jenis Gymnopetalum di Borneo}

a. Daun berlekuk dalam; bunga berbulu pendek dan tersebar. Buah melonjong, kulit buah berusuk atau berlingiran. Biji membundar telur Gymnopetalum chinense

b. Daun mengutuh atau berlekuk sangat dangkal; bunga berbulu halus dan rapat. Buah membulat, kulit buah berwarna hijau muda dan gelap membentuk garis. Biji melonjong Gymnopetalum scabrum

Gymnopetalum chinense (Lour.) Merr.

Gymnopetalum chinense (Lour.) Merr., Philipp. J. Sci. (1919) 256; W.J.de Wilde \& Duyfjes, Blumea 51 (2006) 283; Reinwardtia 12 (2008) 268, Fl. Thailand 9, 4 (2008) 443. Fl. Males. 1, 19 (2010) 71 - Evonymus chinensis Lour., Fl. Cochinch. (1790) 156. - Type: Untraced. Neotype: Levine 1705 (holo A, designated by De Wilde \& Duyfjes, Reinawardtia (2008); iso L), South China.

Bryonia cochinchinensis Lour., Fl. Cochinch. (1790) 595. - Gymnopetalum cochinchinensis (Lour.) Kurz, J. Asiat. Soc. Bengal, Pt. 2, Nat. Hist. 40 (1871) 57; C.B. Clarke in Hook.f., Fl. Birt. Ind.2 (1879) 611; Cogn. In A.DC. \& C.DC., Monogr. Phan. 3 (1881) 391; Ridl., Fl. Malay Penin. 1(1922) 846; Craib, Fl. Siam. 1 (1931) 755; Backer in Backer \& Bakh.f., Fl. Java 1 (1964) 302. - Type: Loureiro s.n. (BM), Vietnam.

Momordica surculata Nooronha, Verh. Batav. Genootsch. Kunsten 4 (1790) 21, nom. Inval.

Gymnopetalum quinquelobum Miq., Fl. Ned. Ind. 1, 1 (1856) 681. - Type: Horsfield s.n. (holo U, barcode U0001464), Java, Soerakarta.

Trichosanthes laciniata Ridl., J.Straits Branch Roy. Asiat. Soc. 59 (1911) 107. - Type: Curtis in Ridley 8350 (holo K, not seen), Peninsular Malaysia, Langkawi.

Persebaran: Tersebar luas, Malesia: Jawa, Sumatra, Borneo, Sulawesi, Kepulauan Sunda Kecil sampai Flores, Semenanjung Malaysia, Singapura, Filipina (de Wilde \& Duyfjes 2010). 
Spesimen yang diamati: Madura, Sampang, Gua Lebar, 30 Januari 2017, Mentari Putri Pratami 01; Brebes, Bumiayu, 07 Februari 2017, Mentari Putri Pratami 04; Kalimantan Timur, Samboja, 25 Februari 2019, Mentari Putri Pratami 06; Kalimantan Timur, Samarinda, Kebun Raya Unmul, 26 Februari 2017, Mentari Putri Pratami 11. berpasir.

Ekologi: Tepi hutan, kebun terbuka, tanah

Fenologi: Tumbuh pada ketinggian $500 \mathrm{~m}$, berbunga dan berbuah sepanjang tahun (de Wilde \& Duyfjes 2010).

Gymnopetalum scabrum (Lour.) W.J.de Wilde \& Duyfjes (Gambar 1)

Gymnopetalum scabrum (Lour.) W.J.de Wilde \& Duyfjes, Reiwardtia 12 (2008) 268; Fl. Thailand 9, 4 (2008) 445; Fl. Males. 1, 19 (2010) 71. - Trichosanthes scabra Lour. Fl. Cochinch. (1790) 589. - Type : Untraced. Neotype: Poilane 111322 (holo P, designated by de Wilde \& Duyfjes, Reinwardtia (2008); iso L), Vietnam, Annam.

Tricosanthes lucioniana Naves ex F.Villar, Fl. Filip., ed. 3 [F.M. Blanco] (1880) Nov. App.: 95, pl. 460 (see note); Merr., Sp. Blancoan. (1918) 13.

Gymnopetalum integrifolium (Roxb.) Kurz, J. Asiat. Soc. Bengal, Pt. 2, Nat. Hist. 40 (1871) 58; C.B. Clarke in Hook.f., Fl. Brit. Ind. 2 (1879) 612; King, J. Asiat. Soc. Bengal, Pt.2, Nat. Hist. 67 (1898)31; Ridl., Fl. Malay Penin. 1 (1922) 846; Cogn. \& Harms in Engl., Pflanzenr. 88, 4.275.2 (1924) 179; W.J.de Wilde \& Duyfjes, Blumea 51 (2006) 286. - Cucumis integrifoliud ('integrifolia') Roxb., Fl. Ind. (1832) 724. - Type: Wallich Cat. 6730 (KW, IDC microfiche), Myanmar, Ponlong.

Gymnopetalum leucostictum Miq., Fl. Ned. Ind. 1,1 (1856) 680; Backer in Backer \& Bakh.f., Fl. Java 1 (1964) 302. - Type : Junghuhn s.n. (lecto L, barcode L0589693, designed by De Wilde \& Duyfjes (2006); iso U, barcode U0001465), Java, Weltevreden.

Herba merambat $0.5 \mathrm{~m}$, batang memiliki rambut padat warna putih sampai kecokelatan; diameter 0.9-2.0 mm. Probact: ada, hijau-kuning, melanset. Sulur tidak bercabang. Daun: panjang tangkai $1.1-2.5 \mathrm{~cm}$; diameter $0.2-0.5 \mathrm{~mm}$; helai daun mem-bundar telur-lebar, berlobus dangkal 5; basal menjantung; ujung membundar, atau agak me-runcing; tepi bergigi; berambut agak jarang dan pendek di bagian atas, bagian bawah berambut padat dan panjang; Perbungaan jantan: bunga tunggal, soliter. Bunga jantan: panjang 6-7 mm tangkai persisten, panjang $30-70 \mathrm{~mm}$; tabung hipantium menyempit ke bawah, berbulu balig abu -abu; daun kelopak segitiga melanset, panjang 4-5 $\mathrm{mm}$; daun mahkota membundar telur, benangsari pada tabung hipantium; panjang filamen 2-2.5 $\mathrm{mm}$; gundul. Bunga betina soliter; panjang tangkai $25 \mathrm{~mm}$; bakal buah membulat, berbulu balig panjang; tabung hipantium silinder, mahkota berwarna putih, panjang mahkota $15 \mathrm{~mm}$; panjang putik 7-10 $\mathrm{mm}$, kepala putik tegak, panjang $2 \mathrm{~mm}$. Buah membulat, panjang $1.5 \mathrm{~cm}$, diameter 12.3 $\mathrm{mm}$; tangkai buah panjang $4.5 \mathrm{~cm}$; diameter 0.8 $\mathrm{mm}$, berbulu pendek, berpola hijau dan hijau muda membentuk garis, jingga-merah ketika matang, berdaging. Biji berwarna cokelat muda-cokelat dan terlindungi oleh plasenta; melonjong, ukuran 4.89 x $2.672 \mathrm{~mm}$, mulus, memiliki lekukan antara permukaan tengah dan tepinya, tepi rata.

Persebaran: Malesia: Jawa, Samboja (Kalimantan Timur), Sulawesi, Lesser Sunda Island (Bali), Semenanjung Malaysia (Penang, Perak, Selangor), Singapura, Filipina (Cebu) (de Wilde \& Duyfjes 2010); India, Sri Lanka, Myanmar, Thailand, Cina selatan, Laos, Cambodia, Vietnam (Gambar 2).

Ekologi: Tepi jalan raya dan dekat sungai.

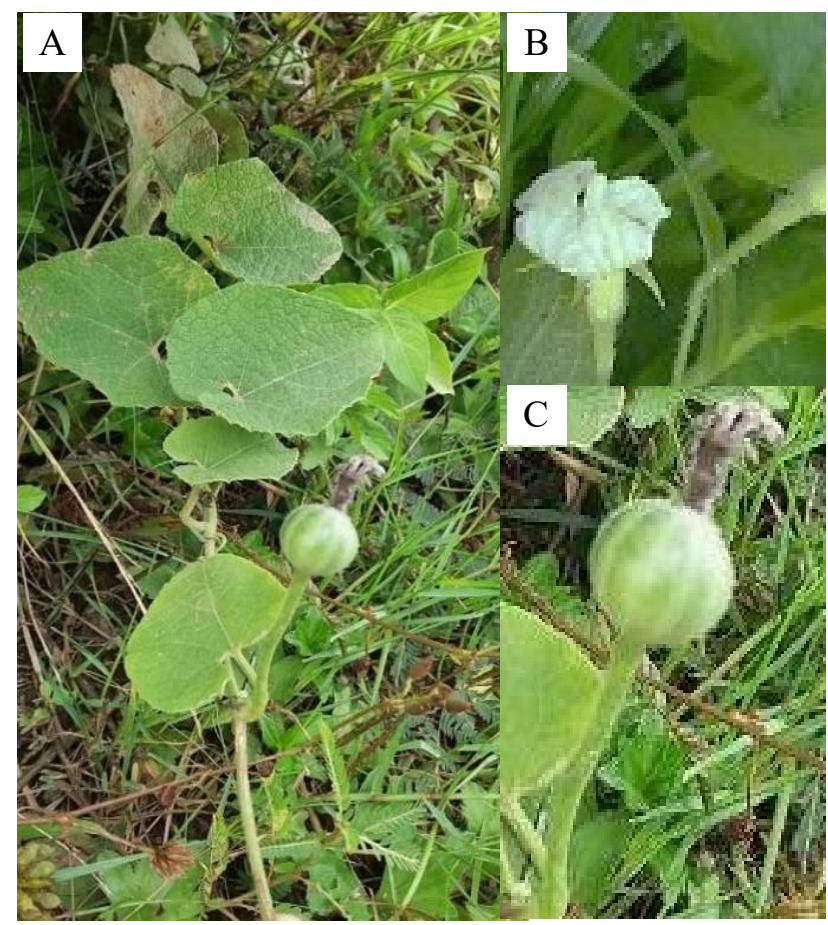

Gambar 1 G. scabrum (Lour.) W.J.de Wilde \& Duyfjes $=$ A. Perawakan, B. Bunga jantan, C. Buah. 


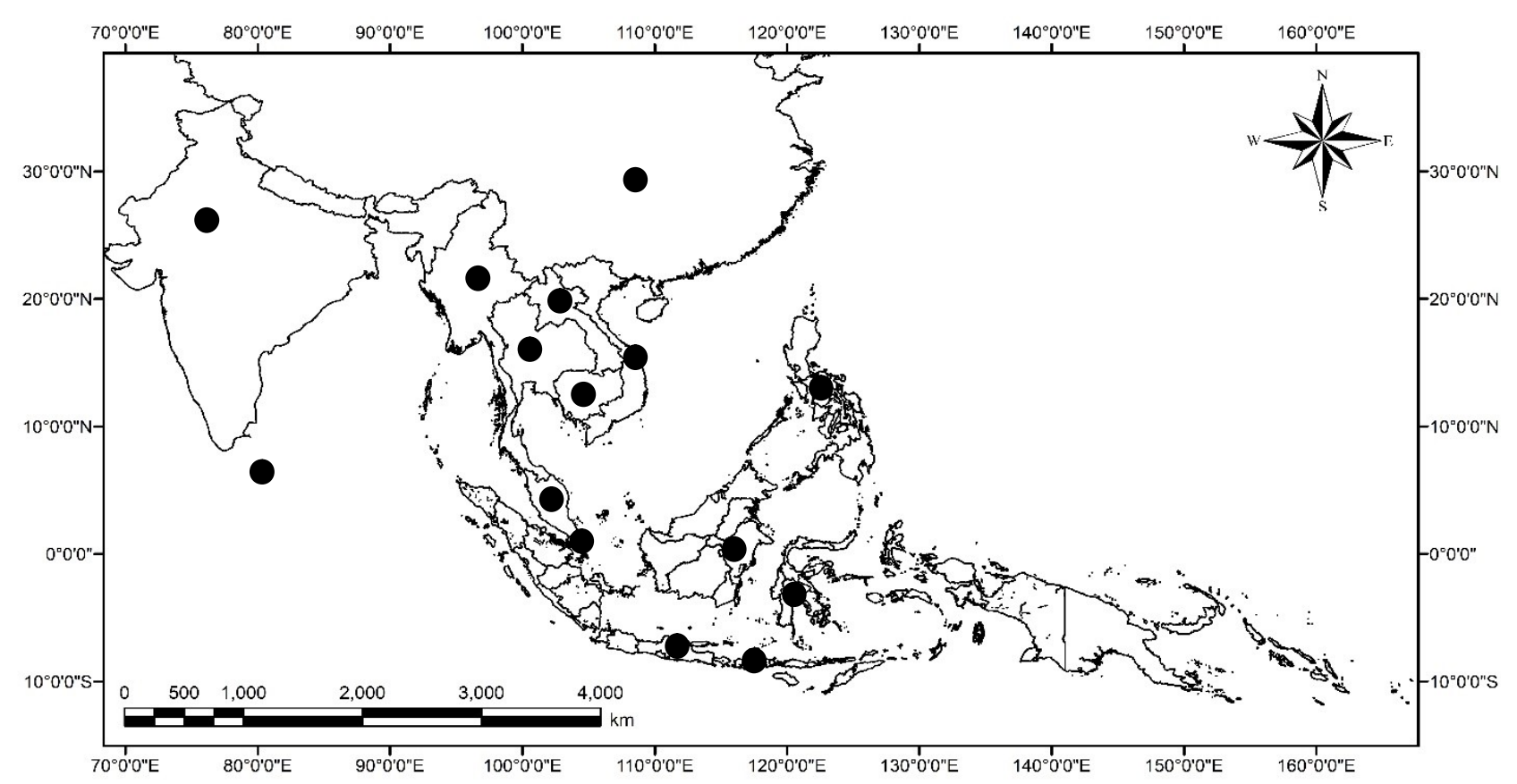

Gambar 2. Peta persebaran G. scabrum.

Fenologi: Berbunga dan berbuah sepanjang tahun (de Wilde \& Duyfjes 2010)

Spesimen: Disimpan di Herbarium Bogoriense (BO) dengan nomer koleksi MHF01

Catatan: G. scabrum dapat dibedakan dari dua jenis terdekatnya yaitu $G$. pectinatum dan $G$. chinense berdasarkan ciri gugusan gagang bunga jantan, ada tidaknya probract, bentuk sepal, panjang tangkai buah, bentuk buah, rambut pada kulit buah, ornamentasi kulit buah, dan bentuk biji. Jenis G. scabrum yang ditemukan di Samboja, Kalimantan Timur memiliki perbedaan pada bebe- rapa ciri dari de Wilde \& Duyfjes (2010) yaitu ukuran daun kelopaknya memiliki ukuran lebih panjang $(5.38 \mathrm{~cm})$ dan melebihi panjang daun mahkotanya (masih kuncup), adanya pola kulit buah loreng hijau muda dan hijau gelap membentuk garis serta tangkai buahnya lebih panjang $(4.5 \mathrm{~cm})$. Meskipun ada perbedaan morfologi (Tabel 1), untuk menetapkan status taksonnya masih perlu penelitian lanjutan dengan pengambilan spesimen baru dengan organ vegetatif dan generatif yang lengkap.

Tabel 1 Perbandingan ciri jenis G. scabrum (Lour.) W.J.de Wilde \& Duyfjes, dan G. chinense (Lour.) Merr.

\begin{tabular}{llll}
\hline \multicolumn{1}{c}{ Ciri } & \multicolumn{1}{c}{$\begin{array}{c}\text { G. scabrum yang } \\
\text { ditemukan di Samboja, } \\
\text { Kalimantan Timur }\end{array}$} & $\begin{array}{l}\text { G. scabrum (Lour.) W.J.de } \\
\text { Wilde \& Duyfjes }\end{array}$ & G. chinense (Lour.) Merr. \\
\hline Gagang bunga jantan & gugusan tegak & $\begin{array}{l}\text { gugusan terdiri atas } \\
\text { beberapa lobus } \\
\text { ada }\end{array}$ & $\begin{array}{l}\text { gugusan tegak dengan } \\
\text { pedicel berbeda } \\
\text { ada }\end{array}$ \\
$\begin{array}{l}\text { Probract } \\
\text { Bentuk daun kelopak }\end{array}$ & segitiga melanset & segitiga melanset & memita, jarang berlobus \\
$\begin{array}{l}\text { Panjang daun kelopak } \\
\text { (mm) }\end{array}$ & $5-6$ & $5-8$ & $6-9$ \\
$\begin{array}{l}\text { Ukuran daun mahkota } \\
\text { bunga (mm) }\end{array}$ & $20 \times 10$ & $20 \times 15$ & $20-30 \times 12-15$ \\
$\begin{array}{l}\text { Panjang tangkai buah (cm) } \\
\text { Bentuk buah }\end{array}$ & 4.5 & $1-3$ & membulat
\end{tabular}


Lanjutan Tabel 1. Perbandingan ciri jenis G. scabrum (Lour.) W.J.de Wilde \& Duyfjes, dan G. chinense (Lour.) Merr.

\begin{tabular}{llll}
\hline \multicolumn{1}{c}{ Ciri } & \multicolumn{1}{c}{$\begin{array}{c}\text { G. scabrum yang } \\
\text { ditemukan di Samboja, } \\
\text { Kalimantan Timur }\end{array}$} & $\begin{array}{l}\text { G. scabrum (Lour.) W.J.de } \\
\text { Wilde \& Duyfjes }\end{array}$ & G. chinense(Lour.) Merr. \\
\hline Rambut pada buah & padat & padat & gundul \\
Ornamentasi kulit buah & $\begin{array}{l}\text { warna hijau muda dan } \\
\text { hijau tua membentuk } \\
\text { garis }\end{array}$ & polos & polos \\
Rusuk pada kulit buah & tidak berusuk & tidak berusuk & berusuk \\
Bentuk biji & melonjong & melonjong & membundar telur \\
\hline
\end{tabular}

\section{UCAPAN TERIMA KASIH}

Ucapan terima kasih kepada Direktorat Jenderal Pendidikan Tinggi (DIKTI) melalui program PMDSU terima kasih atas kepercayaannya untuk memberikan beasiswa selama menempuh pendidikan pascasarjana di IPB.

\section{DAFTAR PUSTAKA}

de Boer H J, Schaefer H, Thulin M \& Renner SS. 2012. Evolution and loss of long-fringed petals: a casestudy using a dated phylogeny of the snake gourds, Trichosanthes (Cucurbitaceae). BMC Evolutionary Biology. 12 (108): 1471-2148.

de Boer Hugo J \& Thulin M. 2012. Synopsis of Trichosanthes (Cucurbitaceae) based on recent molecular phylogenetic data. Phytokeys 12(2952): 23-33.

de Wilde WJJO \& Duyfjes BEE. 2006. Mukia Arn (Cucurbitaceae) in Asia, in Particular in Thailand. Thai For. Bull (Botany) 34: 38-52.

de Wilde WJJO \& Duyfjes BEE. 2010. Flora Malesiana Cucurbitaceae Series 1 Vol. 19. Leiden (NL): Netherlands Centre for Biodiversity Naturalis (section NHN), Leiden University. de Wilde WJJO \& Duyfjes BEE. 2016. Review of the Genus Gymnopetalum (Cucurbitaceae). Blumea 51: 281-296.

de Wilde WJJO, Duyfjes BEE \& Rugayah. 2015. Gymnopetalum pectinatum (W.J. de Wilde \& Duyfjes) Rugayah: Rank of Species for Gymnopetalum scabrum var. pectinatum (Cucurbitaceae). Reinwardtia 14(2): 323324.

Harris JG \& Harris MW. 2006. Plant Identification Terminology. An Illustration Glossary. Utah (US): Spring Like Publishing.

Radford AE. 1986. Fundamental of Plant Systematis. New York (US): Harper \& Row Publisher.

Rifai MA \& Puryadi D. 2008. Glosarium Biologi. Ed ke-2. Jakarta (ID): Pusat Bahasa, Departemen Pendidikan Nasional.

Rugayah, Retnowati A, Windadri FI \& Hidayat A. 2004. Pengumpulan Data Taksonomi. Dalam: Rugayah, Widjaja EA, Praptiwi (eds). Pedoman Pengumpulan Data Keanekaragaman Flora. Bogor (ID): Pusat Penelitian Biologi-Lembaga Ilmu Pengetahuan Indonesia. 